\title{
Anti-Francisella tularensis DNA aptamers detect tularemia antigen from different subspecies by Aptamer-Linked Immobilized Sorbent Assay
}

\author{
Jeevalatha Vivekananda and Johnathan L Kiel \\ Air Force Research Laboratory, HEPC, Brooks City-Base, TX, USA
}

\begin{abstract}
Aptamers are powerful candidates for molecular detection of targets due to their unique recognition properties. These affinity probes can be used to recognize and bind to their targets in the various types of assays that are currently used to detect and capture molecules of interest. They are short single-stranded (ss) oligonucleotides composed of DNA or RNA sequences that are selected in vitro based on their affinity and specificity for the target. Using combinatorial oligonucleotide libraries, we have selected ssDNA aptamers that bind to Francisella tularensis subspecies (subsp) japonica bacterial antigen. F. tularensis is an intracellular, nonmotile, nonsporulating, Gram-negative bacterial pathogen that causes tularemia in man and animals. Just as antibodies have been used to detect specific targets in varying formats, it is possible that nucleic acid-binding species or aptamers could be used to specifically detect biomolecules. Aptamers offer advantages over antibody-based affinity molecules in production, regeneration and stability due to their unique chemical properties. We have successfully isolated a set of 25 unique DNA sequences that specifically bind to $F$. tularensis subspecies japonica. When tested in a sandwich Aptamer-Linked Immobilized Sorbent Assay (ALISA) and dot blot analysis, the aptamer cocktail exhibited specificity in its ability to bind only to tularemia bacterial antigen from subspecies japonica, holarctica (also known as palaearctica) and tularensis but not to Bartonella henselae. Moreover, there is no binding observed either to pure chicken albumin or chicken lysozyme. Thus, it appears that this novel antitularemia aptamer cocktail may find application as a detection reagent for a potential biological warfare agent like $F$. tularensis.

Laboratory Investigation (2006) 86, 610-618. doi:10.1038/labinvest.3700417; published online 20 March 2006
\end{abstract}

Keywords: DNA aptamers; Francisella tularensis; SELEX; ALISA; ELISA; dot blot; bioterrorism

Aptamers are single-stranded oligonucleotides with a length of tens of nucleotides, obtained by systemic evolution of ligands by exponential enrichment (SELEX) technology, exhibiting high affinity and specificity towards any given target molecule. ${ }^{1,2}$ These single-stranded (ss) nucleic acid molecules have highly defined tertiary structures, which allow them to form stable and specific complexes with a range of different targets including small molecules such as amino acids to highly complex proteins and whole viruses. ${ }^{3-7}$ For example, DNA-binding species have been selected that can interact with thrombin ${ }^{8}$ and RNA aptamers have been selected that recog-

Correspondence: Dr J Vivekananda, PhD, HEPC, Air Force Research Laboratory, 2486 Gillingham Dr, Bldg 175 E, Brooks City Base, TX 78235, USA.

E-mail: jeevalatha.vivekananda@brooks.af.mil

Received 9 September 2005; revised and accepted 10 February 2006; published online 20 March 2006 nize a variety of cytokines. ${ }^{9}$ These specialized molecules are analogs to antibodies in specificity and affinity with an apparent advantage of being reproduced by chemical synthesis and more easily labeled with fluorescent or other reporters during their synthesis. Comparisons of various ligandbinding aptamers with proteins that bind to their targets have shown that both nucleic acids and proteins use similar strategies for the formation of well-defined binding patterns. ${ }^{10,11}$ Structural studies with aptamer-target complexes have demonstrated insights into molecular diversity associated with nucleic acid architecture and molecular recognition. ${ }^{12}$ Aptamers frequently form complexes that have dissociation constants in the nanomolar range and can clearly distinguish between even closely related protein targets. ${ }^{13,14}$ The degree of molecular distinction achieved by aptamers may surpass that of antibodies with a remarkable diversity in structure and function. ${ }^{15}$ 
The concept of ss oligonucleotides as affinity molecules for proteins or other ligands was first described by Turek and Gold ${ }^{1}$ and Ellington and Szostak $^{2}$ wherein they explained the ability of short sequences to fold in the presence of a ligand into unique three-dimensional structures that bind a target with high affinity and specificity. Following the incubation of a target with a library of DNA sequences, typically ranging from $10^{14}$ to $10^{18}$ molecules in complexity, target-DNA complexes are isolated, the DNA is amplified and the process is repeated until the desired sample is enriched with sequences that display high affinity and specificity for the target of interest. Since the selection stringency for this in vitro process of evolution is high affinity for the target, aptamers with low picoto nanomolar-binding constants are often obtained. Aptamers offer advantages over antibody-based affinity due to the nature of DNA/RNA, which provides for increased stability, easy regeneration (PCR or chemical synthesis) and simple modifications for detection and neutralization. On the contrary, antibodies in general are stable only under physiological conditions and any modifications often effect or decrease in affinity for targets.

Francisella tularensisis is an encapsulated, small Gram-negative nonmotile Coccobacillus ${ }^{16}$ that causes tularemia, a severe disease of humans and other mammals including squirrels, cats and prairie dogs. Additionally, this organism has an enzootic cycle involving wild animals such as rodents and blood sucking insects. ${ }^{17,18}$ Humans can acquire tularemia through contact with infected animals. ${ }^{19,20}$ It is a facultative intracellular bacterium that has been reported to infect macrophages, liver and related cells. ${ }^{21,22}$ Most common infections in humans are caused by two main subspecies, tularensis and holarctica. ${ }^{23}$ These organisms are highly infectious; fewer than 25 organisms are capable of causing disease when spread by aerosol. ${ }^{24}$ Interest in $F$. tularensisis has increased recently because of its potential use as an agent of biological warfare. ${ }^{25}$

Transmission of this organism to the human population can occur through insect bites, contaminated water sources or handling of infected animals. In spite of its high infectivity, human cases of tularemia are rare. However, its extreme hardiness, infectivity and the ability to cause lethal disease by aerosol raise serious concern that this organism can be exploited by terrorists as a possible biological weapon. As a result, tularemia bacteria is one of the high ranking pathogens categorized by the Centers for Disease Control as a category A agent, meaning it could have the greatest impact on public health if it were used as a weapon of mass destruction. ${ }^{26}$ Human tularemia manifests itself in a variety of syndromes, most of them depending on the portal of infection. The clinical appearance varies from skin lesions to multi-organ involvement. Furthermore, the severity depends on the dose and the virulence of the pathogen. F. tularensis subspecies holarctica (type B), which is spread over the northern hemisphere, is less virulent than $F$. tularensis sub tularensis (type A), which is distributed mainly in North America and is associated with a severe and generally fatal form of tularemia. In particular, the typhoid and pneumonic forms are the most deadly with mortality that can exceed $30 \%$ if patients are left untreated. ${ }^{26}$

Here, we report the selection of 25 unique DNA aptamers that are specific to $F$. tularensisis subspecies japonica antigen that can be used as a screening tool for detection and identification of tularemia bacterial antigen with detection limits as low as $25 \mathrm{ng}$ using optical detection. Further, we demonstrate the ability of our aptamers to bind to three different subspecies of F.t; japonica and holarctica, which generally cause a milder form of tularemia; and F. tularensis (SCHU 4-type A), which causes a lethal form of tularemia. ${ }^{27}$ The aptamers bind with high affinity and specificity, and we detail their application in Aptamer-Linked Immobilized Sorbent Assay (ALISA) and dot blot assays. Thus, aptamers may represent a new class of reagents that could be used in detection and diagnostic platforms that were dominated by antibodies previously.

\section{Materials and methods}

F. tularensis subspecies japonica killed bacterial antigen and its antiserum, trypticase soy broth (TSP), Brain heart infusion (Difco), the glycerol production and agglutination test kits were purchased from Becton Dickinson and Company, Sparks, MD, USA. F. tularensis subspecies holarctica live vaccine strain (type B) was obtained from the Centers for Disease Control and Prevention (CDC) (live vaccine strain Lot \#11, NDBR 101 Lot 0200). F. tularensis subspecies tularensis (SCHU 4-type A) was received from Peter Emanuel of the Critical Reagent Collection of the Department of Defense Joint Program in Chemical and Biological Defense. F. tularensis type B (\#38) was isolated from a cat in Houston, TX, USA. Bartonella henselae (ATCC Number 49882) was purchased from American Type Culture Collection, Manassas, VA, USA. Bovine serum albumin fraction $\mathrm{V}$, chicken albumin, lysozyme from chicken egg and other chemicals were obtained from Sigma. A synthetic random DNA library, biotin labeled primers and other primers were from Sigma/Genosys, The Woodlands, TX, USA. Dot blot reagents and nitrocellulose membranes and biospin disposable chromatography columns were from Bio-Rad, Hercules, CA, USA. Reagents for PCR were purchased from PGC Scientific (Gaithersburg, MD, USA) and Applied Biosystems (Foster City, CA, USA). The TOPO cloning kit was from Invitrogen, Carlsbad, CA, USA. QIAprep spin columns were from Qiagen Inc., Valencia, CA, 
USA. Streptavidin-conjugated alkaline phosphatase, streptavidin-conjugated horseradish peroxidase (HRP), goat anti-rabbit IgG-conjugated HRP, goat anti-rabbit IgG-conjugated alkaline phosphatase, immunopure streptavidin, carbonate buffer and Superblock Buffer were from Pierce Biotechnology, Rockford, IL, USA. Fluor-coated TLC plates for UV shadowing were purchased from Ambion, Austin, TX, USA.

\section{Bacterial Strains and Sample Preparation}

F. tularensis subspecies holarctica live culture from CDC was grown in brain heart infusion media with $0.1 \%$ cystine. Tubes were incubated at $37^{\circ} \mathrm{C}$ with $5 \%$ $\mathrm{CO}_{2}$. After $48 \mathrm{~h}$ growth samples were boiled for $1 \mathrm{~h}$ to heat kill viable organisms. Killed bacteria were centrifuged at $6000 \mathrm{rpm}$ in a sorvall ss34 rotor for $30 \mathrm{~min}$. The bacterial pellet was washed with phosphate-buffered saline (PBS) once and finally resuspended in PBS and stored at $-80^{\circ} \mathrm{C}$ until further use. Formalin-killed F. tularensis subspecies japonica bacterial suspension was washed with PBS twice and resuspended in PBS for further use. To prepare total bacterial protein lysate, the suspension was frozen in liquid nitrogen and thawed on ice. The samples were freeze-thawed for two more times and vortexed for $1 \mathrm{~min}$ and used. An aliquot of the lysate was used to determine total protein concentration. All the lysates were stored at $-80^{\circ} \mathrm{C}$ until further use. $F$. tularensis subspecies tularensis (SCHU 4) was supplied in PBS in the concentration of $10^{8}$ bacteria $/ \mathrm{ml}$. B. henselae was grown in tryptic soy broth (TSB) media at $37^{\circ} \mathrm{C}$ in a $5 \% \quad \mathrm{CO}_{2}$ incubator without shaking. F. tularensis (type B) isolated from cat serum was grown in the same media as subspecies holarctica at $37^{\circ} \mathrm{C}$.

\section{Random Library and Primers}

A 102-base ssDNA template containing 42 bases of random sequence flanked by defined primer-binding sites 5'-ACC CCT GCA GGA TCC TTT GCT GGT ACC NNNN $(N=42)$ AGT ATC GCT AAT CAG TCT AGA GGG CCC CAG AAT-3' was synthesized by Sigma/Genosys. The pool was then amplified via polymerase chain reaction (PCR) using $5^{\prime}$ biotin labeled and $3^{\prime}$ primers and it was further purified by denaturing polyacrylamide gel electrophoresis. After UV shadowing, ssDNA bands were cut and eluted from the gel. Following ethanol precipitation, the ssDNA pool was recovered by centrifugation at $4^{\circ} \mathrm{C}$ and resuspended in Tris-EDTA (TE) buffer and finally used in the in vitro selection process.

\section{In Vitro Selection Procedure}

Iterative rounds of selection and amplification of ssDNA aptamers were performed as described previously by Vivekananda and Kiel. ${ }^{28}$ In brief, to exclude filter binding ssDNA sequences from the pool, the DNA was passed through a $0.45 \mu \mathrm{m}$ HAWP filter (Millipore, Bedford, MA, USA) and washed with an equal volume of binding buffer containing $20 \mathrm{mM}$ Tris-HCL, $\mathrm{pH} 7.5,45 \mathrm{mM}$ sodium chloride, $3 \mathrm{mM}$ magnesium chloride, $1 \mathrm{mM}$ ethylenediaminetetra acetic acid (EDTA), $1 \mathrm{mM}$ diothiothreitol (DTT). In the present study, ssDNA pools of 500 pmol for initial rounds and 200 pmol for later rounds were used in the selection process. ssDNA pools were heat-denatured at $94^{\circ} \mathrm{C}$ for $3 \mathrm{~min}$, and then cooled immediately to $4^{\circ} \mathrm{C}$ in binding buffer. Selection was performed by incubating ssDNA pools with $100 \mu \mathrm{g}$ of total bacterial protein (killed bacteria) at room temperature for $1 \mathrm{~h}$ in binding buffer by gentle rotation. After $1 \mathrm{~h}$ the aptamer-bacterial antigen complex was vacuum-filtered over a HAWP filter at 5 p.s.i. and washed three times with binding buffer. ssDNA that had been retained on the filter was eluted with $7 \mathrm{M}$ urea, $100 \mathrm{mM}$ MES (4-morpholine-ethansulfonic acid ( $\mathrm{pH}$ 5.5)) and $3 \mathrm{mM}$ EDTA by boiling. Eluted ssDNA was then precipitated with an equal volume of isopropyl alcohol. Selected ssDNAs were amplified by PCR and used for the next round of selection. After round 10, the pool was amplified by PCR and the product was cloned using a Topo TA cloning kit (Invitrogen, Carlsbad, CA, USA). The cloned sequences were transformed into Escherichia coli. In all, 35 colonies were picked randomly and the plasmid DNA was purified by mini-prep Qiagen kit and sequenced. In all, 25 unique sequences were obtained and used for further analyses.

\section{Aptamer-Linked Immobilized Sorbent Assay}

Sandwich ALISA assays were performed in 96-well microtiter plates (Corning, supplied by Fischer Scientific, Houston, TX, USA). The selected aptamer cocktail was coated with a concentration of $500 \mathrm{pmol} /$ well and the non-specific sites were blocked with Superblock (Pierce Biotechnology). In brief, a cocktail of aptamer stock was made by reconstituting the lyophilized aptamers in sterile distilled water. The cocktail was then diluted to desired concentration in carbonate buffer $\mathrm{pH} 9.4$ (Pierce Biotechnology). In all, $100 \mu \mathrm{l}$ of the solution containing aptamers was added to each well in a 96well clear plate and incubated for $2 \mathrm{~h}$ at room temperature. After the designated time, $100 \mu \mathrm{l}$ of Superblock blocking buffer was then added on top of the aptamer solution. Plates were allowed to stand for an additional $30 \mathrm{~min}$ at room temperature. The contents were discarded from the plates and washed once with $200 \mu \mathrm{l}$ of Superblock blocking buffer and dried.

Prior to the binding assay, the wells were further blocked with 1\% BSA in PBS for $30 \mathrm{~min}$ at room temperature. Various quantities ranging from $25 \mathrm{ng}$ to $2 \mu \mathrm{g}$ of total bacterial antigen from $F$. tularensisis subspecies japonica, were incubated for $1 \mathrm{~h}$ at room temperature by gentle shaking in $100 \mu \mathrm{l}$ of binding 
buffer containing $20 \mathrm{mM}$ Tris-HCL, pH 7.5, $45 \mathrm{mM}$ sodium chloride, $3 \mathrm{mM}$ magnesium chloride, $1 \mathrm{mM}$ EDTA, $1 \mathrm{mM}$ diothiothreitol (DTT). After the designated time, unbound target was removed and the plates were washed twice with $0.1 \%$ Tween-20 in PBS (phosphate-buffered saline/Tween (PBS-T)). After the final wash, biotin-labeled aptamer cocktail was then added to the individual wells at a concentration of $500 \mathrm{pmol} /$ well. The plates were further incubated at room temperature for another hour. Unbound biotin aptamers were removed and the plates washed twice with PBS-T. Finally $100 \mu \mathrm{l}$ of a 1:1000 dilution of a solution of streptavidin conjugated to HRP were added to the individual wells. Following 30-min incubation at room temperature on a shaking platform, wells were washed twice with PBS-T and developed using ABTS as substrate (Sigma) according to the manufacture's instructions, and absorbance was read at $405 \mathrm{~nm}$ using Synergy ${ }^{\mathrm{TM}}$ HT Multi-Detection Microplate Reader from BIO-TEK. Antigens from F. tularensis subspecies holarctica and tularensis (SCHU 4) were used to assess the specificity of the aptamers. $B$. henselae, chicken albumin and chicken lysozyme were used as negative controls.

\section{Enzyme-Linked Immunosorbent Assay}

To compare aptamer cocktail vs anti-tularemia antibodies, we developed a sandwich Enzymelinked Immunosorbent Assay (ELISA) assay using commercially available $F$. tularensis rabbit antiserum (Becton-Dickinison and Company). Antiserum was diluted to $1: 1000$ with carbonate-bicarbonate buffer (pH 9.0). Ninety-six-well microtiter plates (Corning) were coated with $100 \mu \mathrm{l}$ of diluted antiserum for $1 \mathrm{~h}$ at $37^{\circ} \mathrm{C}$. The wells were washed further with PBS-T (0.01\%; pH 7.2) and blocked with Superblock for $30 \mathrm{~min}$ and dried at room temperature. Following further blocking with 1\% BSA in PBS, F. tularensis subspecies japonica antigen was added to the wells in quantities ranging from 25 to $500 \mathrm{ng}$, and 1 to $2 \mu \mathrm{g}$ in PBS. After an incubation of $1 \mathrm{~h}$ at room temperature, wells were washed with PBS-T three times. After removal of unbound antigen, the wells were probed with anti-tularemia rabbit IgG at a dilution of 1:1000 for $1 \mathrm{~h}$. After plates had been washed thrice with PBS-T, $100 \mu \mathrm{l}$ of horseradish peroxidase (Pierce Biotechnology, Rockford, IL, USA) conjugated goat anti-rabbit IgG at a dilution of 1:5000 was added to the wells and allowed to bind for $30 \mathrm{~min}$. After three washes with PBS-T, the enzymatic reaction was started with $100 \mu \mathrm{l}$ of ABTS (Sigma) according to the manufacturer's recommendation. $\mathrm{OD}_{405}$ values were determined using a microplate reader from BIO-TEK. As for the ALISA, antigens from subspecies holarctica and tularensis (SCHU 4) were used in the ELISA. Bartonella henselae, chicken albumin and chicken lysozyme were used as negative controls.

\section{Dot Blot Analysis with Aptamers and Antibodies}

Fifty $\mu \mathrm{g}$ of bacterial lysate from $F$. tularensis subspecies holartica, \#38 isolate and tularensis (SCHU 4) were spotted onto nitrocellulose membrane discs and allowed to air dry. These samples were fixed under vacuum at $80^{\circ} \mathrm{C}$ for $1 \mathrm{~h}$ and blocked with 5\% BSA in PBS. One batch was incubated with biotin-labeled aptamer cocktail at $500 \mathrm{pmol} /$ disc in binding buffer $(20 \mathrm{mM}$ Tris-HCl, $\mathrm{pH}$ 7.5, $45 \mathrm{mM}$ sodium chloride, $3 \mathrm{mM}$ magnesium chloride, $1 \mathrm{mM}$ EDTA, $1 \mathrm{mM}$ DTT) for $1 \mathrm{~h}$ at room temperature with gentle rocking. The other batch was probed with anti-tularemia rabbit IgG (BectonDickinson and Company) in PBS at a dilution of 1:1000 for $1 \mathrm{~h}$. After the designated time, both batches of membrane discs were washed with PBS$\mathrm{T}$ three times and probed with streptavidin-conjugated alkaline phosphatase (Pierce Biotechnology, Rockford, IL, USA), and goat anti-rabbit IgG-conjugated alkaline phosphatase (Pierce Biotechnology, Rockford, IL, USA), respectively, for $30 \mathrm{~min}$. Excess enzyme was removed by three subsequent washes with PBS-T. Finally, the membrane discs were developed with 5-bromo-4-chloro-3-indolylphosphate/nitro blue tetrazolium (BCIP/NTB)-BLUE (Sigma). Bartonella henselae, chicken albumin and chicken lysozyme were used as negative controls.

\section{Results}

\section{Selection of Anti-Tularemia Aptamers from Combinatorial Library}

DNA aptamers specific for $F$. tularensis subspecies japonica were selected from a library of ssDNA with a 42 -nucleotide random region flanked by $27-n t 5^{\prime}$ and 30-nt $3^{\prime}$ fixed regions for PCR amplification. The initial library theoretically contained $10^{14}-10^{16}$ different sequences. Amplification was performed with biotin labeled primer $F\left(5^{\prime}\right)$ and nonbiotinlabeled primer R $\left(3^{\prime}\right)$ during SELEX selection. For our application, we choose to use DNA rather than RNA sequences because, with and without terminal modifications, they have been shown to be effective in biological fluids and are generally nuclease resistant. ${ }^{8,29-31}$

We used F. tularensis subspecies japonica antigen because this is the only type available for tularemia detection by the commercially available test kit. Prior to the selection process, the ssDNA pool was amplified to enrich the sequence pools. Upon mixing with the tularemia antigen, oligomers from the library may bind to the target DNA. During this process a bound candidate or candidates of the pool may be specific for the target and can be amplified with primers $\mathrm{F}$ and R. The number of PCR cycles was also optimized to avoid over-amplification. The stringency of the selection was controlled by adjusting the antigen concentrations, buffer conditions and the washes. During the process of binding 
and amplification, there is a possibility that some of the sequences can bind nonspecifically to the membranes. To circumvent this problem, negative selection was performed after rounds 3, 6 and 9 by passing DNA pool through nitrocellulose filters. Biotinylated DNA sequences exhibiting affinity to the target were captured by agarose-conjugated streptavidin beads. The affinity selection was stopped after 10th round, and the candidates from the pool were cloned. In all 35, randomly picked clones were isolated and the segment of DNA exhibiting unique sequences was sequenced. Out of 35 sequences, 25 were unique and the remaining 10 were duplications.

\section{Binding Affinity of DNA Aptamers to F. tularensis subspecies japonica by Aptamer-Linked Immobilized Sorbent Assay (ALISA)}

To determine the affinity of the selected polyclonal DNA aptamer cocktail for $F$. tularensis japonica antigen we developed an Aptamer-Linked Immobilized Sorbent Assay. This assay provided a rapid assessment of the relative binding capabilities of this aptamer cocktail. Additionally, this enzymatic assay (ALISA) was used to provide information of specificity of these aptamers to tularemia antigen from other subspecies.

In this format, a nonbiotinylated aptamer cocktail was immobilized as a capture aptamer as described in the methods. Tularemia antigen from subspecies japonica was added to the wells with quantities ranging from $25 \mathrm{ng}$ to $2 \mu \mathrm{g}$. Target molecule sensitivity was assessed for these aptamers by determining their binding affinity. Binding reaction was carried out as described in the earlier section. Employing a colorimetric detection system (ABTS) for horseradish peroxidase activity conjugated to streptavidin, we observed a significant signal over background, and data for four replicate samples ranged from 0.0451 (background) to 1.667 absorbance units. As seen in Figure 1, it is further confirmed that the antigen affinity to the aptamer cocktail is directly proportional to the quantity of antigen. It is evident from the data that aptamers exhibit impressive binding affinities for subspecies japonica achieving an unusually strong association even at $25 \mathrm{ng}$ of total antigen. While it is clear that the detection limit depends primarily on the binding affinity of aptamers for the target, the formation of an affinity-based complex is also a crucial step in producing signal. In order to achieve an absolute assessment of target molecule sensitivity in terms of number of bacteria, an ALISA was performed with subspecies holarctica. Here, various concentrations of bacteria were prepared by serial dilution with PBS and used in the binding assay. The data presented in Figure 2 demonstrate that the sensitivity and detection of the target is attained as low as $1.7 \times 10^{3} / \mathrm{ml}$ of bacteria. It is interesting and

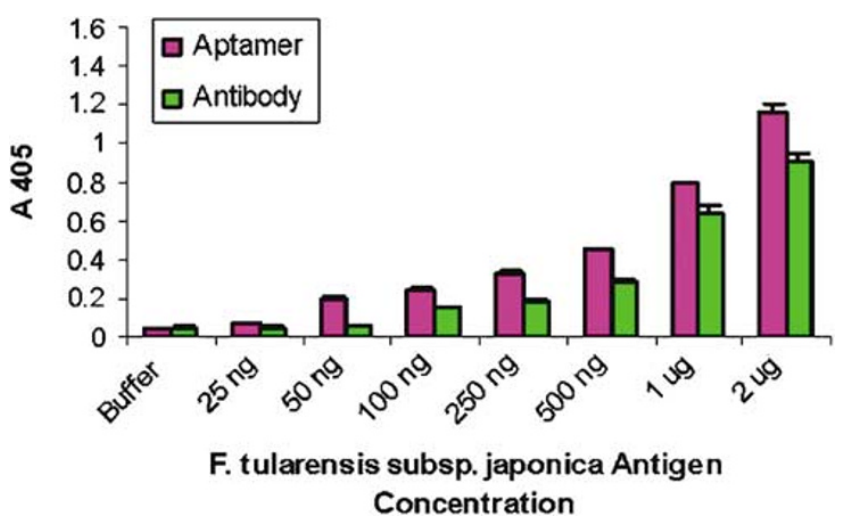

Figure 1 Sensitivity of anti-tularemia aptamer cocktail for $F$. tularensis subspecies japonica antigen and anti-tularemia antiserum as assessed by ALISA and ELISA. The assays were performed as described in 'Materials and methods'. The data are presented as OD at $405 \mathrm{~nm}$ vs antigen quantity. Averages of four replication measurements are shown in the figure.

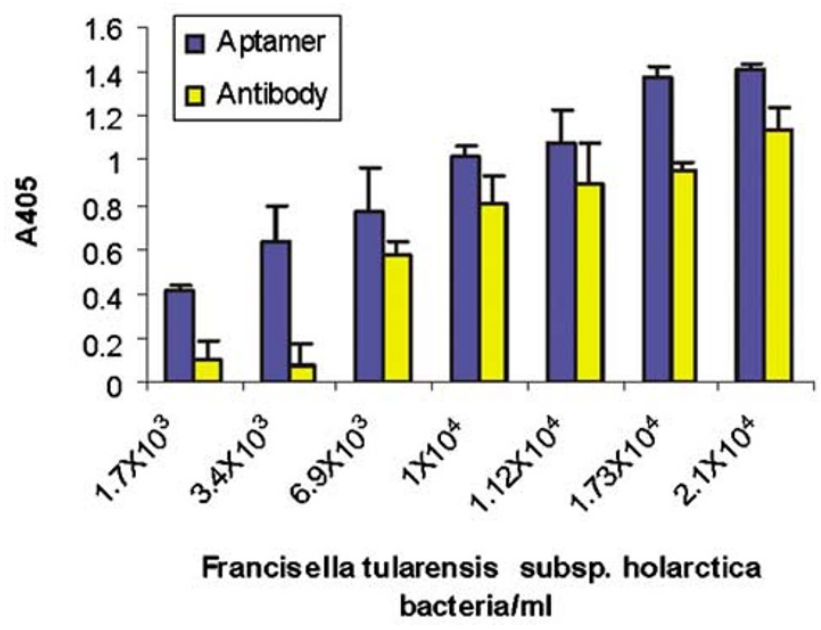

Figure 2 Tularemia bacterial antigen binding to anti-tularemia aptamer cocktail and anti-tularemia polyclonal antibodies as assessed by ALISA and ELISA using HRP activity. The assays were performed as described in 'Materials and methods'. The bacterial antigen used in the binding assay was prepared from $F$. tularensis subspecies holarctica (live vaccine strain). The data are plotted as OD at $405 \mathrm{~nm}$ vs number of bacteria/ml. Averages of triplicate measurements are shown in the figure.

perhaps paradoxical to note that these two different subspecies exhibited a similar binding affinity thereby indicating the detection capability of aptamers in this platform across the subspecies.

In order to verify the specificity of the aptamer cocktail to other F. tularensis subspecies, we tested the binding affinity of these aptamers against antigens from two other subspecies holarctica, tularensis (SCHU 4), and another isolate (\#38) type B (Houston, TX, USA) which was positive for agglutination and negative for glycerol fermentation. Also the isolate \#38 was further confirmed as type B by PCR amplification of ISFtu2 element using the CDC's primer sequences (data not shown). ${ }^{32}$ The 
specificity of the aptamer cocktail was further evaluated by ALISA using antigens from three other subspecies listed earlier. As can be seen in Figure 3 the signal output is ranging from 1.256 for subspecies tularensis (SCHU 4) to 2.144 absorbance units for subspecies holarctica, indicating a substantial homology with common motifs for binding and cross reactivity between the subspecies. Finally, to rule out the nonspecificity of the aptamers, antigen from unrelated bacteria and other pure proteins were used in the assay. Sandwich ALISA and ELISA assays were carried out with total antigen from $B$. henselae a rod-shaped Gram-negative bacteria showed a very low affinity. However $B$. henselae exhibited some nonspecific binding with both aptamer and antibody. This most likely is due to some similar bacterial wall components because both of these bacteria are Gram negative. In contrast, pure proteins like chicken albumin and lysozyme showed no affinity with an optical density close to background.

\section{Anti-Tularemia Polyclonal Antibody Specificity for Tularemia Antigen by ELISA}

To compare aptamer specificity to that of antibodies, we performed a sandwich ELISA using commercial antiserum. The ELISA plates were coated with antitularemia rabbit antiserum as described in methods. Identical quantities of subspecies japonica total antigen are used in the binding assay. The data presented in Figure 1 indicates that antibody is not as sensitive as aptamer cocktail. Furthermore, the detection limit for aptamer cocktail is $25 \mathrm{ng}$ whereas the detection limit for antibody was $100 \mathrm{ng}$ of antigen. Similar to aptamers, antibody exhibited concentration-dependent signal output in the ELISA. An attempt was made to assess the binding affinity of antibody to other related and unrelated antigens. To compare the detection capability of antibody in terms of bacterial cell number, similar to ALISA, whole $F$. tularensis holarctica antigen was used in the ELISA. In this assay, the diagnostic performance of the ELISA is inferior to the ALISA as depicted in Figure 2. While the aptamer cocktail can detect $1.7 \times 10^{3}$ bacteria $/ \mathrm{ml}$, (Absorbance units $=0$. 413), the threshold for antibody detection is $6.9 \times 10^{3}$ bacteria $/ \mathrm{ml}$ (Absorbance units $=0.568$ ). Further binding assays with identical quantitiess of total antigen from all the three subspecies holarctica, japonica and tularensis (SCHU 4) along with unrelated $B$. henselae and pure proteins from chicken were performed to compare the ELISA to the ALISA. As shown in Figure 3, the antibody detected the antigen from all the three subspecies of F. tularensis by generating positive signal in the enzymatic assay. As expected, there were negative signals for pure proteins from chicken. Additionally, we observed some nonspecific binding to $B$. henlselae. This could be partly due to the fact that the

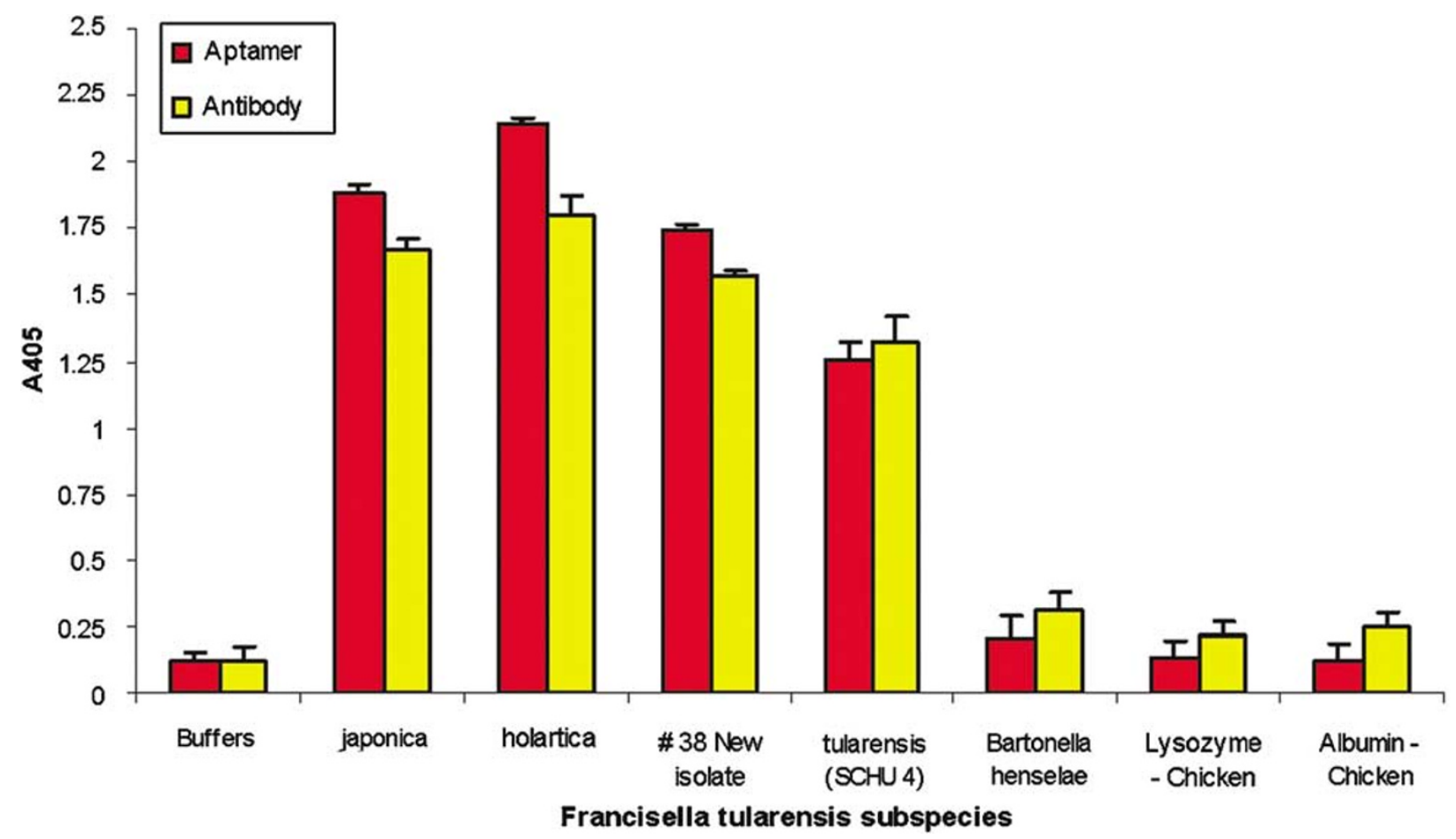

Figure 3 ALISA and ELISA to analyze the specificity of anti-tularemia aptamer cocktail. The assays were performed as described in 'Materials and methods'. Antigen from both type A and B of $F$. tularensis are used in the analysis. Subspecies include holarctica, \#38 (type B) a new isolate from Houston, tularensis (SCHU 4) and an unrelated Gram-negative rod shaped bacteria B. henselae. Additional negative controls include chicken lysozyme and chicken albumin. 
serum may have had some products binding nonspecifically to the bacteria. The other notable observation under identical conditions is that the antibody exhibited a higher level of nonspecific binding affinity with albumin and lysozyme (Figure 3) compared to aptamer cocktail, indicating significant advantages of aptamers over their antibody counterparts. Although antibody-based detection systems are available, the presented data reinforce the superior performance of the aptamer-based detection/diagnostic system.

\section{Comparisons of the Specificity of the Anti-Tularemia Aptamer Cocktail to Anti-Tularemia Polyclonal Antibody Using Dot Blot Analysis}

The results of the ALISA and ELISA suggested that the anti-tularemia aptamer cocktail exhibited specificity for tularemia antigen irrespective of their source. In order to verify the specificity and to further investigate the potential uses of the aptamers, we performed a dot blot analysis (Figure 4). In all, $50 \mu \mathrm{g}$ of total protein from the bacterial lysate from subspecies holarctica, \#38, tularensis along with $B$. henselae, chicken lysozyme and chicken albumin were spotted onto nitrocellulose discs and air dried at room temperature. To test the exquisite binding specificity of aptamers compared to their counterpart antibodies, we also performed parallel immuno dot blot assay with anti-tularemia antiserum. The immobilized proteins were probed with biotin labeled aptamer cocktail and detected with streptavidin conjugated alkaline phosphatase. Parallel blots were treated with tularemia antiserum and developed with alkaline phosphatase conjugated goat anti-rabbit antibody. As shown in Figure 4, the signal/color produced by the aptamer cocktail and antibody showed strong affinity to tularemia bacterial lysate but did not show any affinity to negative controls, thereby indicating their specificity towards the antigens of different subspecies of $F$. tularensis. Interestingly, in this particular technique, the performance of the aptamer cocktail was similar to that of antibody.

\section{Discussion}

In the present study, $F$. tularensis was selected as a target because of its high bioterrorism potential. ${ }^{26}$ Monitoring of the environment for biological threats, such as $F$. tularensis requires molecular probes that bind to the agents and ensures their presence and detection in the field. Aptamer technology is based on the principle that biological agents whether bacterial cells or spores or viruses have unique surface markers that can bind to these molecular probes from diverse pools or libraries through screening and selection methods. ${ }^{33}$ Nucleic acid aptamers would be effective because of their affinity and specificity for the binding pockets of the targets with proper folding. ${ }^{34}$ These unique probes have been shown to discriminate closely related molecules from their targets and also exhibit chiral discrimination of target molecules. ${ }^{35}$ The effectiveness of this emerging technology has been illustrated by development of diagnostic probes for various infectious agents including bacterial and viral targets. ${ }^{36}$ In our present investigation, we selected DNA aptamers rather than RNA aptamers because of their stability in harsh environments and because they can be used easily in the field. It is also reasonable to assume that DNA aptamers without further modifications could perform better in detection and diagnostic assays in which the aptamers may come in contact with different biological

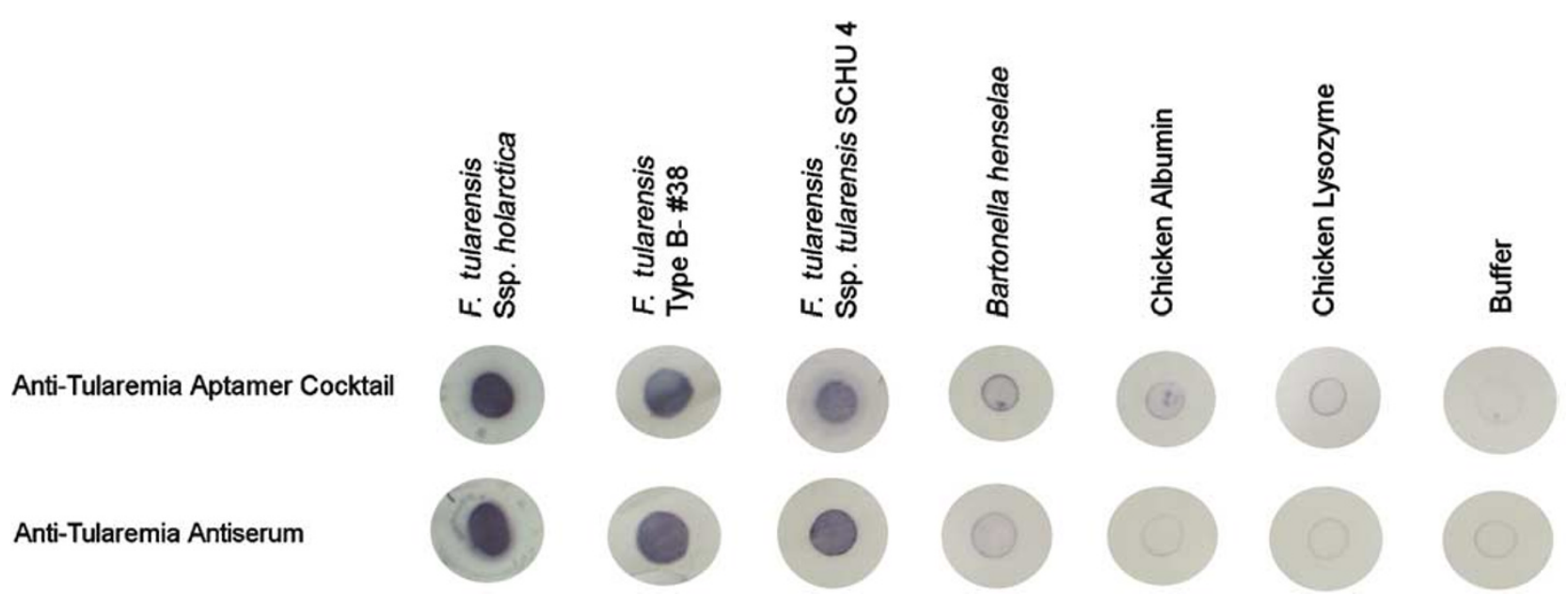

Figure 4 Specificity of anti-tularemia aptamer cocktail and anti-tularemia antiserum assessed by dot blot analysis. Fifty micrograms of total protein from $F$. tularensis subspecies holarctica, F. tularensis type B an isolate (\#38) from Cat (from Houston, TX), F. tularensis subspecies tularensis (SCHU 4), B. henselae, chicken albumin and chicken lysozyme were spotted onto nitrocellulose membrane discs and probed with either aptamer cocktail or anti-tularemia rabbit antiserum and analyzed by alkaline phosphatase activity by using 5bromo-4-chloro-3-indolylphosphate/Nitro Blue Tetrazolium (BCIP/NTB)-Blue as described in 'Materials and methods'. 
samples for a brief period of time. Although other types of detection and diagnostic platforms utilizing peptides and antibodies are available, DNA-based technology may be better suited for the detection of bio-warfare agents and environmental monitoring, in which robust, nonperishable and inexpensive reagents capable of operating in severe and extreme environmental conditions are needed.

Enzyme linked assays provide a means of quickly evaluating the binding affinity. As early as 1996, Drolet et $a l^{37}$ reported the first enzyme-linked aptamer assay (ELAA) consisting of a mixed ELISA/ELAA sandwich to detect human vascular endothelial growth factor on a microtiter plate. Later they demonstrated that the aptamers can be used to specifically detect isoforms of the same protein expressed due to an alternate splicing of the mRNA. ${ }^{37}$ Since then, similar assays have been demonstrated using either labeled or immobilized nucleic acid molecules as capture or detecting agents. Aptamer conjugated immunoassays using other platforms to detect specific proteins were reported earlier by Rye et al and Yang et al. ${ }^{38,39}$ The most remarkable applications were the demonstration of fiber-optic microarray biosensor using aptamers by Lee and Walt ${ }^{40}$ and an aptamer-based quartz crystal biosensor. ${ }^{41}$

Recently, Grunow et $a l^{42}$ reported the detection of $F$. tularensis in biological specimens using capture ELISA, whereas Porsch-Özcürümez et $a l^{43}$ compared different detection methods including ELISA to identify $F$. tularensis from human samples. However, all of these technologies need more instrumentation involvement. Serology is the only test performed currently for the diagnosis of tularemia in humans but it is of limited value. Nonetheless, these tests do not differentiate between type A and B, as there is no antigenic difference between them. ${ }^{44}$ None of these reports utilized nucleic acid-based enzymatic assays. In our study with aptamer sandwich assays, we are able to measure significant signals over very low background by using biotinylated aptamers to detect tularemia antigen in a 96well microtiter plate format. Our findings suggest that in terms of detection test efficiency, ALISA is superior to ELISA. Very recently similar findings were reported by Baldrich et $a l^{45}$ in a displacement enzyme linked aptamer assay using thrombin that demonstrated the superior performance of aptamers compared to antibodies.

Using aptamers in blot analysis is another means to study the affinity and specificity to the target. We have tested the aptamer cocktail for their binding affinity to tularemia antigen from different sub species along with unrelated Gram-negative bacteria and chicken albumin and chicken lysozyme by dot blot analysis with alkaline-phosphatase conjugated enzymatic assays. The aptamer cocktail showed no cross reactivity to either lysozyme or chicken albumin. Although the antibody detection system is the gold standard for protein detection and identification, the data presented in this study reinforces the superior performance of the nucleic acid-based diagnostic system.

In summary, we have generated a subpopulation of oligonucleotide anti-ligands that bind with high specificity to $F$. tularensis antigen. These ssDNA molecules specifically recognize tularemia antigen from three different subspecies japonica, holarctica and tularensis (SCHU 4) and do not bind to other Gram-negative bacteria like $B$. henselae. The current work demonstrates that aptamers can be used in an ALISA format for detection of specific targets. Although antibodies have been the reagent of choice for detection and diagnostic assays, the increased specificity of aptamers might make these nucleic acids attractive alternatives to detect various targets. It is important to point out that aptamers have an unlimited potential to circumvent limitations associated with antibodies. In conclusion, it is reasonable to expect that the ALISA platform generated by aptamers will pave the way for future detection systems in which antibodies have previously dominated.

\section{Acknowledgements}

We would like to thank Ms Melanie D Woitaske, Ms S Kathryn Boyd, and Ms Shelly D Roper of Conceptual Mind Works Inc. for graphics, MSgt Mark S Wade and Ms Amy M Heathman for supplying bacterial antigen, and $\mathrm{Dr}$ Ramesh Ganapathy, Pierce Biotechnology for coating microtiter plates. This work was sponsored in part by the Department of Defense's Joint Service Technology Base Program in Chemical and Biological Defense and the Air Force Office of Scientific Research.

\section{References}

1 Turek C, Gold L. Systemic evolution of ligands by exponential enrichment: RNA ligands to bacteriophage T4 DNA polymerase. Science 1990;249:505-510.

2 Ellington AD, Szostak JW. In vitro selection of RNA molecules that bind specific ligands. Nature 1990;346: 818-822.

3 Famulok M. Oligonucleotide aptamers that recognize small molecules. Curr Opin Struct Biol 1999;9: 324-329.

4 Osborne SE, Ellington AD. Nucleic acid selection and the challenge of combinatorial chemistry. Chem Rev 1997;97:349-370.

5 Famulok M. Molecular recognition of amino acid by NA-aptamers: An L-citruline binding RNA motif and its evolution into an L-arginine binder. J Am Chem 1994;116:1698-1706.

6 Burgstaller P, Famulok PM. Isolation of RNA aptamers for biological co-factors by in vitro selection. Angew Chem, Int Ed Engl 1994;33:1084-1087.

7 Joshi PJ, Fisher TS, Prasad VS. Anti-HIV inhibitors based on nucleic acids: emergence of aptamers as 
potent antivirals. Curr Drug Targets Infect Disord 2003;4:383-400.

8 Bock LC, Griffin LC, Latham JA, et al. Selection of single-stranded DNA molecules that bind and inhibit human thrombin. Nature 1992;335:564-566.

9 Green LS, Jellinek D, Bell C, et al. Nuclease-resistant nucleic acid ligands to vascular permeability factor/ vascular endothelial growth factor. Chem Biol 1995; 10:683-695.

10 Hermann T, Patel DJ. Adaptive recognition by nucleic acid aptmers. Science 2000;287:820-825.

11 Marshall KA, Robertson MP, Ellington AD. A biopolymer by any other name would bind as well: a comparison of the ligand-binding pockets of nucleic acids and proteins. Structure 1997;5:729-734.

12 Gold L, Polisky B, Ublenbeck O, et al. Diversity of oligonucleotide functions. Annu Rev Biochem 1995; 64:763-797 (Review).

13 Uphoff KW, Bell SD, Ellington AD. In vitro selection of aptamers: the dearth of pure reasons. Curr Opin Struct Biol 1996;3:281-288 (Review).

14 Jenison RD, Gill SC, Pardi A, et al. High-resolution molecular discrimination by RNA. Science 1994; 263:1425-1429.

15 Gesteland RF, Atkins JF (eds). The RNA World. Plainview. Cold Spring Harbor Lab Press: NY, 1993.

16 Cross JT, Penn RL. Francisella tularensisis (Tularemia). In: Bennet JE, Dolin R and Mandell GL (eds). Mandell, Douglas and Bennett's Principles and Practice of Infectious Diseases. Philadelphia: Churchill Livingstone, 2002, pp 2393-2401.

17 Ellis JPC, Oyston M, Green M, et al. Tularemia. Clin Microbiol Rev 2002;15:631-646.

$18 \mathrm{La}$ Regina M, Lonigro J, Wallace M. Francisella tularensis infection in captive, wild caught prairie dogs. Lab Anim Sci 1986;36:78-80.

19 Magee JS, Steele RW, Kelly NR, et al. Tularemia transmitted by a squirrel bite. Pediatr Infect Dis J 1989; 8:123-125.

20 Quenzer RW, Mostow SR, Emerson JK. Cat-bite tularemia. JAMA 1977;238:1845.

21 Conlan JW, North RJ. Early pathogenesis of infection in the liver with the facultative intracellular bacteria Listeria monocytogenes, Francisella tularensis and Salmonella typhimurium involves lysis of infected hepatocytes by leucocytes. Infec Immun 1992; 60:5164.

22 Fortier AH, Green SJ, Polsinelli T, et al. Life and death of an intracellular pathogen: Francisella tularensis and macrophage. Immunol Ser 1994;60:349.

23 Ellis J, Oyston PCF, Green M, et al. Tularemia. Clin Microbiol Rev 2002;15:631-646.

24 Tarnvik A. Nature of protective immunity to Francisella tularensis. Rev Infect Dis 1989;11:440.

25 Dennis DT, Inglesby TV, Henderson DA, et al. Tularemia as a biological weapon: medical and public health management. J Am Med Assoc 2001;285:2763.

26 Rotz LD, Khan AS, Lillibridge SR, et al. Public health assessment of potential biological terrorism agents. Emeg Infect Dis 2002;8:225.

27 Isherwood KE, Titball RW, Davies DH, et al. Vaccination strategies for Francisella tularensis. Adv Drug Delivery Rev 2005;57:1403-1414.
28 Vivekananda J, Kiel JL. Methods and components for aptamers against anthrax. Patent 6,5696,30 B1 issued on May 27, 2003.

29 Tasset DM, Kubik MF, Steiner W. Oligonucleotide inhibitors of human thrombin that bind distinct epitopes. J Mol Biol 1997;272:688-698.

30 Griffin LC, Toole JJ, Leung LLK. Discovery and characterization of a novel nucleotide-based thrombin inhibitor. Gene 1993;137:25-31.

31 Hicke BD, Watson SR, Koenig A, et al. DNA aptamers block L-selectin function in vivo. J Clin Invest 1996;98: 2688-2692.

32 Petersen JM, Schriefer ME, Carter LG, et al. Laboratory analysis of tularemia in wild-trapped, commercially traded prairie dogs, Texas, 2002. Emerging Infectious Diseases 2004;10:419-425.

33 Ivnitski D, O’Neill DJ, Gattuso A, et al. Nucleic acid approaches for detection and identification of biological warfare and infectious disease agents [Review]. Biotechniques 2003;35:862-869.

34 Huang DB, Vu D, Cassidy LA, et al. Crystal structure of N-kB (P50)2 complexed to a high-affinity RNA aptamer. Proc Natl Acad Sci USA 2003;100: 9268-9273.

35 Jenison RD, Gill SC, Pardi A, et al. High-resolution molecular discrimination by RNA. Science 1994;263: 1425-1429.

36 Petrenko VA, Sorokulova IB. Detection of biological threats. A challenge for directed molecular evolution [Review]. J Microbial Methods 2003;58:147-168.

37 Drolet DW, Moon-McDermott L, Romig TS. An enzyme-linked oligonucleotide assay. Nat Biotechnol 1996;8:1021-1025.

38 Rye PD, Nustad K. Immunomagnetic DNA aptamer assay. Biotechniques 2001;30:290-295.

39 Yang X, Li X, Prow TW, et al. Immunofluorescence assay and flow-cytometry selection of bead-bound aptamers. Nucleic Acids Res 2003;31:e54.

40 Lee M, Walt DR. A fiber-optic microarray biosensor using aptamers as receptors. Anal Biochem 2000;282: 142-146.

41 Liss M, Petersen B, Wolf $\mathrm{H}$, et al. An aptamer-based quartz-crystal protein biosensor. Anal Chem 2002;74: 4488-4495.

42 Grunow R, Splettstoesser W, McDonald S, et al. Detection of Francisella tularensis in biological specimens using capture enzyme-linked immunosorbant assay, an immuno-chromatographic handheld assay and PCR. Clin Diag Lab Immunol 2000;7: 86-90.

43 Porsch-Özcürümez $\mathrm{M}$, Kischiel $\mathrm{N}$, Priebe $\mathrm{H}$, et al. Comparison of enzyme-linked immunosorbent assay, western blotting, muicroglutination, indirect immunofluorescence assay and flow cytometry for serological diagnosis of tularemia. Clin Diag Invest Immunol 2004; 11:1008-1015.

44 Mörner T, Sandström G. Tularemia. Manual of Diagnostic Tests and vaccines for terrestrial animals. World Organization for Animal Health (OIE) Part 2, Ch. 2.8.2. 2004.

45 Baldrich E, Acero JL, Reekmans G, et al. Displacement enzyme linked aptamer assay. Anal Chem 2005;77: 4774-4784. 